\title{
Cibercultura e as influências das redes sociais virtuais na escolha de destinos turísticos: direcionamentos a partir de teorias sociológicas dos laços sociais
}

\section{Cyberculture and the influences of virtual social networks in the choice of tourist destinations: directions based on sociological theories of social ties}

\author{
Marcelo Ferreira Trezza Knop (KNOP, M. F. T.) ${ }^{*}$ e \\ Juliane Santos Machado (MACHADO, J. S.) ${ }^{* *}$
}

\begin{abstract}
RESUMO - A partir de uma concepção complexa e interdisciplinar da realidade esta pesquisa, realizada da metade ao final do ano de 2015 na cidade de Juiz de Fora (Minas Gerais, Brasil), tratou da relação de teorias sociológicas dos laços sociais e seus desdobramentos nas redes sociais virtuais, mais especificamente, no processo de escolha de um destino turístico pelas pessoas; bem como das influências e compreensão do comportamento de indivíduos e grupos neste ambiente. Desta forma, a mesma apresenta como objetivo geral, analisar a influência das redes sociais virtuais no comportamento de escolha de destinos turísticos por indivíduos. A metodologia, de base quantitativa, adotou, para coleta de dados, o método survey, com a escolha não aleatória de 200 entrevistados e, para análise dos mesmos, estatísticas de distribuição de frequência e tabulação cruzada, com cálculo do coeficiente de correlação qui-quadrado. Como principal resultado pôde-se perceber que as redes sociais virtuais têm grande influência no processo de decisão de destinos turísticos por indivíduos, a partir de seus relacionamentos nas redes sociais, principalmente a partir de sua rede de amigos e familiares, ou seja, de seus laços fortes.
\end{abstract}

Palavras-chave: Cibercultura; Redes sociais virtuais; Destinos turísticos; Teorias dos laços.

ABSTRACT - From a complex and interdisciplinary conception of reality, this research, carried out from half to the end of 2015 in the city of Juiz de Fora-MG, deals with the relation of sociological theories of social ties and it unfolding in virtual social networks, more specifically, in the process of choosing a tourist destination by people; as well as the influences and understanding of the behavior of individuals and groups in this environment. In this way, it presents as general objective, to analyze the influence of virtual social networks on the behavior of choice of tourist destinations by individuals. The methodology used, of quantitative basis, used, for the data collection,

\footnotetext{
Formação: Graduação em Administração pela Universidade Federal de Juiz de Fora (UFJF). Especialização em Métodos Estatísticos Computacionais pelo Instituto de Ciências Exatas da Universidade Federal de Juiz de Fora (ICE/UFJF). Mestrado em Administração, linha de pesquisa, Organizações, Gestão e Sociedade, pela Universidade Federal de Lavras (UFLA). Doutorando em Ciências Sociais, linha de pesquisa, Políticas Públicas e Desigualdade, pela Universidade Federal de Juiz de Fora (UFJF). Atividade profissional: Professor do Departamento de Turismo da Universidade Federal de Juiz de Fora (UFJF). Endereço físico para correspondência: Rua Abrahim Camilo Ayupe, 251. CEP. 36680-000 - São João Nepomuceno - Estado de Minas Gerais (Brasil). E-mail: marceloknop@gmail.com

** Formação: Graduação em Ciências Humanas e Turismo pela Universidade Federal de Juiz de Fora (UFJF). Mestranda em Turismo, linha de pesquisa, Turismo, Planejamento e Gestão, pela Universidade Federal Fluminense (UFF). Endereço físico para correspondência: Rua Aladir Soares da Silva, 90 (Bairro Quintas da Avenida). CEP. 36046-590 - Juiz de Fora - Estado de Minas Gerais (Brasil). E-mail: julianejf-13@hotmail.com
} 
the survey method, with the non-random choice of 200 interviewees and, for it analysis, statistics of frequency distribution and cross tabulation, with calculation of the chisquare correlation coefficient. As a main result, it was possible to perceive that virtual social networks have a great influence on the decision process of tourist destinations by individuals, from their relationships in social networks, mainly from their network of friends and family, that is, from their strong ties.

Key words: Cyberculture; Virtual social networks; Tourist destinations; Theories of ties. 


\section{INTRODUÇÃO}

De acordo com a Secretaria de Comunicação Social (SECOM, 2016), pesquisando indivíduos em todas as regiões do país, com 16 anos ou mais, a internet foi o segundo meio de informação mais utilizado pelos entrevistados (26\% da amostra), perdendo apenas e ainda para a televisão (63\% dos entrevistados). Destes, $50 \%$ utilizaram a internet sete dias por semana, e 29\% acessaram a mesma 300 minutos por semana; sendo $72 \%$ através de telefone celular, $25 \%$ pelo computador e $3 \%$ via tablet. Também, a busca de informações em formato digital, como jornais e revistas, ocorreu em 30 e $26 \%$ dos casos, respectivamente. Isso mostra, inicialmente, a internet como importante meio de informação e comunicação em nível nacional. É indiscutível, portanto, a presença e influência da internet e das mídias sociais no dia a dia da sociedade brasileira, como influência nas decisões dos indivíduos, sejam eles pessoas físicas, grupos ou entes empresariais. Destaque para o advento e importância das redes sociais virtuais, onde atividades, interesses e opiniões são expostos diariamente para essa comunidade que, a cada dia, aumenta seu número de usuários.

Pode-se afirmar, portanto, que o ambiente do ciberespaço e das redes sociais expandiu-se nas mesmas proporções, tornando-se um meio propício para o compartilhamento de experiências vivenciadas e da solidificação de laços sociais, através do acesso às comunidades online, estreitando a proximidade dos indivíduos com os grupos com os quais mais se relacionam.

Assim, a partir de uma concepção complexa e interdisciplinar da realidade e, consequentemente, dos argumentos construídos em variadas obras, tornou-se foco de estudo deste trabalho a relação de teorias sociológicas dos laços sociais e seus desdobramentos nas redes sociais virtuais, mais especificamente, no processo de escolha de um destino turístico; bem como das influências e compreensão do comportamento de indivíduos e grupos neste ambiente.

Neste sentido, este trabalho apresenta o seguinte problema de pesquisa: haveria influência das redes sociais virtuais no comportamento dos consumidores, em relação às escolhas dos destinos turísticos para suas viagens? A partir deste problema, o trabalho apresenta como objetivo geral analisar a influência das redes sociais virtuais no comportamento de escolha de destinos turísticos por indivíduos. Mais especificamente, 
descrever o perfil sociodemográfico e de uso da internet e das redes sociais virtuais dos respondentes da pesquisa; analisar qual a influência dos posts nestas redes (imagens, vídeos e comentários) na escolha de um destino turístico por eles; e qual grupo, entre desconhecidos, conhecidos, amigos, familiares e empresas, teve mais influência nestas decisões.

Consequentemente, este trabalho foi motivado, em grande parte, pelo grande avanço que as tecnologias de informação e comunicação vêm incorporando à sociedade moderna e, especificamente, ao setor de turismo.

\section{REFERENCIAL TEÓRICO}

O referencial teórico deste estudo, de base complexa e interdisciplinar, baseou-se incialmente, como forma de contextualização, na concepção de cultura, a partir de abordagem simbólica e, após, no neologismo cibercultura. Após adotou-se, como recorte teórico do estudo, teorias e conceitos de base funcionalista, que abrangeriam a relação turismo e as mídias sociais, com destaque para as redes sociais virtuais; finalmente, destacou-se as teorias dos laços sociais de Granovetter e Krackhardt, a partir de paradigma interpretativo da realidade social.

\subsection{CULTURA CIBERNÉTICA - CIBERCULTURA}

O surgimento da palavra cultura reside na sociedade romana, onde a expressão latina colere referia-se ao cultivo de produtos relacionados com a terra, a educação, o desenvolvimento da infância e o cuidado com os Deuses (FLEURY; SAMPAIO, 2002). Os mesmos autores afirmam que já no contexto do mercantilismo e da expansão imperialista o conceito começa a ser empregado para designar o entendimento de costumes, línguas, crenças e mitos de povos diferentes, visando o estabelecimento de relações comerciais e de dominação. Também, que neste período, os estudos de cultura deparam-se com a noção de diversidade e apoiam-se em algumas ideias de Darwin, tentando assim justificar o surgimento de culturas superiores, determinando, consequentemente, a dominação política e econômica que começara a emergir. 
Mas, com o passar dos anos, seu significado fora se modificando. Deste modo, nos dias atuais, o termo cultura pode ser entendido em diferentes níveis de manifestação, como por exemplo, a cultura de um povo ou de um país, ou seja, de grupos que possuem estilos de vida próprios, sendo ilusório tentar esgotar o conceito (DURHAN, 1984; MORGAN, 1996; FLEURY; SAMPAIO, 2002). Neste sentido, a cultura pode ser entendida como "um conjunto complexo e multidimensional de praticamente tudo o que constitui a vida em comum nos grupos sociais" (AKTOUF, 1994, p. 49), ou seja, a cultura implica uma interdependência entre história, estrutura social, condições de vida e experiência intersubjetiva das pessoas. Mais especificamente, a cultura pertence ao domínio da significação, pois, apesar de ser uma ideação, não existe na cabeça de alguém e, embora seja não física, não é uma identidade oculta, pois, a ação do homem é vista como uma ação simbólica, ou seja, uma ação que significa. Assim, o homem, enquanto animal simbólico, está preso a teias de significados que ele mesmo teceu, assumindo a cultura como sendo essas teias, não em busca de leis, mas sim, de significados (GEERTZ, 1989; SCHULTZ; GRUYTER, 1995).

Já o conceito cibercultura tem sua origem e evolução ligados a Pierre Lévy (1997). Assim, o autor delimita os conceitos de ciberespaço e cibercultura, caracterizando o primeiro como uma nova alternativa de comunicação digital, abarcando toda a gama de informações que este universo contém, tornando-se, então, um ambiente favorável ao desenvolvimento do segundo termo, a cibercultura; este abrangeria um conjunto de técnicas, atitudes e valores que cresceram e se desenvolveram, concomitantemente à evolução do ciberespaço, o que faz com que estes conceitos estejam amplamente ligados um ao outro. Ou seja, as tecnologias digitais surgiram, como a infraestrutura do ciberespaço, novo espaço de comunicação, de sociabilidade, de organização e de transação, mas também, novo mercado de informação e de conhecimento (LÉVY, 1997).

Tais conceitos e características, como destacados anteriormente, influenciaram e influenciam a sociedade e, consequentemente, o comportamento de indivíduos que demandam produtos turísticos (neste caso, destinos turísticos), pois o turismo é considerado um grande incorporador de tecnologias em diferentes segmentos. É possível contar, por exemplo, com ferramentas que avaliam a relação "destino $\mathrm{x}$ 
cliente", como o site TripAdvisor, com as diversas mídias sociais e com os chamados sites de ofertas de acomodações, como os sistemas virtuais Booking.com e Trivago, que comparam os preços do valor da diária dos meios de hospedagem de determinado destino turístico, além dos diversos sites, blogs e redes sociais que tratam do assunto. Por exemplo, de acordo com Guimarães e Borges (2008), informações sobre destinos turísticos, horários de voos e hotéis são alguns exemplos dos produtos do turismo que se adéquam à ferramenta internet, uma vez que é possível consultá-los em tempo real. Essa quantidade de informações disponíveis em um mundo virtual torna-se vital para as organizações, que devem expor e oferecer seus produtos 24 horas por dia.

Portanto, não há dúvidas de que o processo turístico, ou seja, do momento que o indivíduo ou grupo sai de casa, até o momento que ele volta, transformou-se com o advento da internet, o surgimento do ciberespaço e as novas tecnologias e comportamentos a eles incorporados. Consequentemente, essas mudanças trouxeram transformações nas formas que até então as empresas que compõem o produto turístico vinham comunicando e influenciando seus clientes e possíveis clientes (seja uma agência, um meio de hospedagem, uma empresa de transporte, um restaurante ou o próprio destino turístico). Isso porque, os atuais clientes, a partir das comunicações online, passaram a não somente ser informados e influenciados, mas, a fazer isso também, ao expor suas atividades, interesses e opiniões através das mídias sociais e sites correlatos, como blogs e comunidades online, por exemplo.

\subsection{TURISMO E MÍDIAS DIGITAIS}

Com o advento da internet e as novas tecnologias de comunicação e informação, a possibilidade inédita de comunicação instantânea, que se encontra disponível em toda a parte do globo, tornou-se possível. Isso desencadeou um efeito positivo sobre a interação social e tendeu a aumentar a exposição a outras fontes de informação (CASTELLS, 1999). Tal disponibilidade de informações em tempo real é possível, devido, em grande parte, ao formato que as informações digitais possuem, facilitando sua propagação a consumidores, fornecedores e, até mesmo, viabilizando a troca dessas mesmas informações entre indivíduos e grupos (GUIMARÃES; BORGES, 2008). Desta forma, o termo mídias digitais é utilizado para descrever esse novo fenômeno, sendo 
delimitado como o tipo de mídia baseado na conversação e interação entre indivíduos online, através de redes sociais, fóruns da internet, blogs sociais, microblogging, wikis, podcasts, fotos, vídeos etc. (MIGUÉNS; BAGGIO; COSTA, 2008; XIANG; GRETZEL, 2010; STRAUSS; FROST, 2012).

No turismo o comportamento do consumidor foi influenciado pelas tecnologias de informação e comunicação, especialmente com o advento da web 2.0, que mudou radicalmente a forma como os indivíduos planejam e consomem produtos relativos a viagens (BUHALIS; LAW, 2008; XIANG; GRETZEL, 2010; BIZIRGIANNIA; DIONYSOPOULOU, 2013; HUDSON et al., 2015 ${ }^{1}$ ), isto é, o turismo online pode ser entendido como compreendendo todas as organizações informacionais relacionadas com viagens (XIANG; WÖBER; FESENMAIER, 2008). Operadores turísticos, consumidores potenciais, produtores e viajantes ativos estão criticando, perguntando e fornecendo conselhos, apresentando propostas, avaliando produtos e serviços e uma série de outras atividades que acontecem no mundo das redes sociais e das novas tecnologias; ou seja, o conceituado consumidor-viajante participa ativamente, não somente como usuário que utiliza o produto turístico, mas também como um comunicador, que expressa sua opinião, uma necessidade ou um desejo nas redes (BIZIRGIANNIA; DIONYSOPOULOU, 2013).

Portanto, as mídias sociais, através dos conteúdos produzidos pelo consumidor (consumer generated content), têm gerado influências nos comportamentos de compra de produtos turísticos, a partir de um modelo igual-para-igual (peer-to-peer), visando o compartilhamento de informações (MIGUÉNS; BAGGIO; COSTA, 2008). Isso quer dizer que os consumidores podem obter informações para auxiliar no processo de planejamento de suas viagens e tomar decisões informadas sobre destinos, acomodações, restaurantes, passeios e atrações no destino (CHUNG; BUHALIS, 2008), sendo as recomendações pessoais muito importantes neste processo (LITVIN; GOLDSMITH; PAN, 2008). Os operadores tradicionais do produto turístico enfrentam, desta forma, um novo consumidor, que pode facilmente acessar informações e compartilhar opiniões e sugestões de modo informal e colaborativo, influenciando o poder de escolha de outros consumidores (MIGUÉNS; BAGGIO; COSTA, 2008).

\footnotetext{
${ }^{1}$ HUDSON, S.; ROTH, M. S.; MADDEN, T. J.; HUDSON, R. The effects of social media on emotions, brand relationship quality, and word of mouth: An empirical study of music festival attendees. Tourism Management, 47, 2015.
} 
Portanto, o setor de turismo é convidado a construir uma nova realidade, investindo em inovação e transparência, já que os usuários deste produto são "bombardeados", constantemente, com uma grande quantidade de informações online, em tempo real (BIZIRGIANNIA; DIONYSOPOULOU, 2013).

\subsection{AS TEORIAS SOCIOLÓGICAS DOS LAÇOS SOCIAIS DE GRANOVETTER E KRACKHARDT}

A especificidade e sua incapacidade ao constituir saberes unitários, que criaram novas formas de entendimento do mundo, baseando-se, consequentemente, na fragmentação e especialização crescentes do conhecimento científico, não conseguem mais abarcar toda a complexidade dos fenômenos sociais/humanos. Portanto, deve-se tentar reverter este quadro anacrônico do pensamento científico, de modo que a sociedade passe a pensar em si própria de maneira mais integrada, complexa e, consequentemente, multiparadigmática (CARVALHO, 2000).

A partir do exposto, uma nova postura ontológica e epistemológica desta ciência deve enfatizar a inter-relação entre paradigmas, rejeitando-se, preliminarmente, a incomensurabilidade dos mesmos. Esta nova orientação enfatiza a visão multiparadigmática, procurando sintetizar diferenças, acenando para análises da ação humana que superem tais dicotomias, visando constituir uma nova visão de realidade que permita aos pesquisadores darem conta da complexidade inerente desta. Esta abordagem multiparadigmática tem a finalidade de integrar partes da ciência que até então não dialogavam, em busca de uma reinterpretação dos contornos sociais, o retorno ao sujeito e a inclusão do imaginário nas análises da realidade (BURREL; MORGAN, 2005).

É neste sentido que neste estudo se pensou dar uma de suas contribuições, ou seja, utilizar teorias sociológicas dos laços sociais para o entendimento das relações e interações nas redes sociais virtuais, apesar de, inicialmente, não terem sido concebidas para o entendimento da relação turismo/mídias sociais; mas que, do ponto de vista dos autores, tem muito a contribuir para a discussão e aprofundamento desta relação. Também, mais especificamente no setor do turismo, devido à influência do ensaio de Minasi e Silveira (2016), que destacaram e evidenciaram as correlações entre a 
formação de redes sociais, a expansão da atividade turística e o desenvolvimento regional.

Seguindo essa discussão interparadigmática, um dos primeiros autores que deve ser acrescentado à discussão é Mark Granovetter (1973). Isso porque, o mesmo analisa a inserção do indivíduo na sociedade e sua interação com os demais indivíduos e grupos. A partir dessa análise, propõe a teoria da "força dos laços fracos", objetivando identificá-los nas redes que conectam as pessoas, visto que é impossível estar inserido em uma sociedade sem relacionar-se com os demais indivíduos nela inseridos. $\mathrm{O}$ autor propõe, portanto, a teoria dos laços que, de acordo com o mesmo, podem ser fortes e ou fracos.

Os laços fracos são mais superficiais e que têm como principal característica a pouca profundidade emocional, mas que agregam valor quando conectam um indivíduo a outros que fornecem diferentes fontes de informação, trazendo novas ideias, comportamentos e inovação (destacando mais importância para estes tipos de laços) (GRANOVETTER, 1973).

Já os laços fortes, como a própria categorização indica, são constituídos por indivíduos e grupos com proximidade a pessoas, como por exemplo, a família, os amigos próximos e demais membros dessa rede com profundo e influente envolvimento emocional com os indivíduos presentes nesse laço. É importante destacar também que, os laços fortes, de acordo com as proposições teóricas do autor, agregam pouco valor quando o indivíduo está buscando inovações, novas informações e recursos. Este fato está relacionado à homogeneidade presente nestas relações, levando sempre à obtenção das mesmas informações. Segundo o mesmo autor, é importante enfatizar também que há uma relação de interdependência entre as redes de laços fracos e fortes, interdependência esta que, muitas vezes, distancia o contraste entre os mesmos. O argumento utilizado pelo autor é que os indivíduos são expostos a inovações e a novas informações presentes nas redes de laços fracos; porém, para que tomem posse de tais inovações, é necessário o aval a partir de suas relações nas redes de laços fortes (GRANOVETTER, 1973).

Um pouco mais adiante, Krackhardt (1992), criticando e ampliando a teoria de Granovetter (1973), propõe a "teoria da força dos laços fortes” e apresenta o conceito de philos. De acordo com o mesmo, a força dos laços fortes está presente em situações de 
severas mudanças e incertezas, sendo que estes laços constituem a base de confiança que podem reduzir a resistência e proporcionar conforto em face da incerteza. Portanto, o autor destaca que a mudança não é facilitada por laços fracos, e sim, por um particular tipo de laço forte, desenvolvendo o conceito de relacionamentos, a partir da palavra grega philos.

O philos designa um particular tipo de laço que, devido a seu caráter especial, tem implicações que o torna diferente dos outros tipos de laços. Neste sentido, o conceito de philos é utilizado pelo autor como um substantivo, ou regras que governam seu uso, sendo similar à palavra "amigo" (friend), devendo seguir três necessárias e suficientes condições: interação, afeição e tempo (KRACKHARDT, 1992).

$\mathrm{O}$ conceito de interação destaca que A e B devem interagir um com o outro, tendo uma grande probabilidade de que cada indivíduo desta relação terá acesso à informação que o outro tem, sendo que estas interações possibilitam oportunidades para troca das mesmas. A e B também devem sentir afeição um pelo outro a partir de relações simétricas, na maioria dos casos; todavia, estas relações, algumas vezes, podem ser assimétricas. Finalmente, A e B devem ter uma história de interações (tempo), que tem duração de mais de um período de tempo, sem afetos de curto prazo em estudos de laboratório, mas delegados para o campo, onde as relações têm tempo suficiente para desenvolver-se. Portanto, a combinação destas qualidades é definida como philos, pois a interação cria oportunidade para a troca de informação; a afeição cria motivação para tratar o outro em caminhos positivos, ou, finalmente, não fazer algo para "ferir" o outro (estresse, desarmonia ou tensão); e o tempo cria a experiência necessária que possibilita cada pessoa influenciar como o outro usará qualquer informação compartilhada. Estes são os ingredientes do "confiar em", que ocorrem em eventos de dois tipos de laços fortes: redes de amizade e aconselhamento (KRACKHARDT, 1992).

\section{METODOLOGIA}

$\mathrm{Na}$ presente pesquisa, optou-se por realizar um levantamento do tipo survey, com base em um corte transversal na realidade estudada. Isso quer dizer que os resultados encontrados são o reflexo do momento em que os dados foram coletados, em 
uma situação específica de tempo e espaço (MALHOTRA, 2001). Também, esta pesquisa apresenta-se como exploratória e descritiva. É exploratória porque seu objetivo é a descoberta de dados (MALHOTRA, 2001), e descritiva, na medida em que pretende descrever os fatos e fenômenos de determinada realidade (TRIVIÑOS, 1992), com adoção de amostragem não-probabilística por conveniência (MALHOTRA, 2001; HAIR et al., 2005) ${ }^{2}$. Em função disto, esta pesquisa apresenta pequeno potencial de generalização, pois, os resultados obtidos neste estudo, de aprofundamento e descrição da realidade, não podem ser extrapolados para outra realidade diferente daquela encontrada, considerando tempo e espaço específicos. Quanto à natureza das variáveis, a pesquisa classifica-se como quantitativa, pois se trabalhou com questionário estruturado, utilizando-se de escalas nominal e ordinal, tendo como base principal, além de variáveis descritoras de perfil sociodemográfico e uso da internet e das redes sociais virtuais, as categorias de análise: "desconhecidos", "conhecidos", “amigos", "familiares" e "empresas", visando identificar diferentes tipos de influência nas redes. Para caracterizar o perfil dos pesquisados, em um primeiro momento, realizou-se uma análise de frequência; em seguida, procedeu-se à análise de correlação bivariada, ou tabulação cruzada (MALHOTRA, 2001, HAIR et al., 2005).

O período de coleta de dados teve duração de 6 meses, envolvendo, ao todo, 200 entrevistados, que se dispuseram a responder à pesquisa em questão.

\section{RESULTADOS E DISCUSSÃO}

De acordo com a proposta do artigo, principalmente de seus objetivos específicos, apresentar-se-á neste tópico os resultados alcançados com a pesquisa de campo. Inicialmente, foram destacados o perfil sociodemográfico e de uso da internet e das redes sociais virtuais dos entrevistados. Após, as influências dos posts nestas redes, e quais deles surtiram mais efeitos no comportamento das pessoas na escolha de um destino turístico para suas viagens; e também aqueles que não tiveram influência. Finalmente, as considerações finais do estudo, delimitando os pontos fortes e fracos da pesquisa e as possibilidades de estudos futuros a partir da leitura do mesmo.

\footnotetext{
${ }^{2}$ HAIR, J. F. Jr.; ANDERSON, R. E.; TATHAM, R. L. T.; BLACK, W. C. Análise Multivariada de
} Dados. 5. ed. Porto Alegre: Bookman, 2005. 593 p. 


\subsection{DESCRIÇÃO DO PERFIL SOCIODEMOGRÁFICO E DE USO DA INTERNET E DAS REDES SOCIAIS VIRTUAIS}

Ao analisar os dados iniciais da pesquisa, percebeu-se que 46,5\% dos respondentes eram do sexo masculino e 53,5\% feminino. A faixa etária predominante foi a de 21 a 25 anos, correspondendo a $24,5 \%$ da amostra, seguida pela faixa de 26 a 30 anos (24\% da amostra); após, pelas faixas de 31 a 35 anos (16,5\%) e acima de 40 anos (16,5\%); e, finalmente, pela faixa etária de 15 a 20 anos (12,5\%) e de 36 a 40 anos (6\%). Em relação ao nível de escolaridade e renda familiar percebeu-se que a maioria apresentou-se entre as categorias "graduação incompleta" (32,7\% dos respondentes) e "graduação completa" $(25,1 \%)$, com renda familiar entre 2 a 5 salários mínimos $(38,2 \%$ da amostra), seguidas pela faixa de 6 a 9 salários mínimos (31,7\% dos entrevistados). Também é importante descrever que $62,5 \%$ da amostra foram de solteiros, $34,5 \%$ de casados e 3\% separados. Dessa forma, pôde-se perceber que a predominância sociodemográfica da pesquisa esteve representada pelo sexo feminino $(53,5 \%)$, na faixa etária de 21 a 30 anos (48,5\%), com renda familiar de 2 a 5 salários mínimos (38,2\%), com grau de instrução entre graduação incompleta e completa (57,8\% dos respondentes) e estado civil na categoria de solteiros $(62,5 \%$ da amostra).

Após, buscou-se analisar o perfil de uso da internet e redes sociais dos respondentes. As variáveis analisadas objetivaram perceber, principalmente, o principal meio de acesso à internet, o tempo diário de navegação, a frequência de acesso às redes sociais digitais e qual destas redes foi mais acessada. Assim, a partir das respostas coletadas, percebeu-se que o principal meio de acesso à internet foi o telefone celular ou smartphone (67,5\% da amostra), com tempo diário de navegação predominante de 1 a 4 horas por dia, representando 55,5\% da amostra, seguido pela categoria "fico conectado o dia todo" (35\% dos respondentes), mostrando, consequentemente, o grande tempo diário de navegação na internet pelos entrevistados. É importante destacar aqui também que a grande maioria daqueles que responderam à pesquisa, mencionaram acessar a rede social todos os dias $(86,5 \%$ da amostra), sendo o Facebook a rede predominantemente acessada, com $83 \%$ dos respondentes, ficando conectados à mesma, na maior parte dos casos, de 1 a 3 horas por dia. 
Ao realizar a correlação entre algumas variáveis descritoras da pesquisa, buscando observar a associação entre grupos de variáveis, como por exemplo, da variável sexo com o principal meio de acesso à internet, percebeu-se que houve correlação entre estas, que é, como dito, o celular. Isso pôde ser percebido, pois, dos 200 entrevistados de ambos os sexos, $136(68 \%)$ utilizaram o celular como principal meio de acesso à internet. Também percebeu-se a associação entre estas categorias, pois o índice de significância estatístico, utilizando o teste não-paramétrico de qui-quadrado, foi de 0,001 (ou seja, inferior que 0,05), mostrando haver correlação entre uso do celular tanto por homens quanto para mulheres. Essa correlação foi confirmada através do cálculo do coeficiente de contingência, que mede a intensidade de associação numa tabela de tamanho arbitrário, sendo seu valor calculado também inferior ao sigma de 0,05, ou seja, com significância estatística de 0,001; portanto, houve correlação estatisticamente significativa entre a variável sexo e o principal meio de acesso à internet, o celular. O mesmo pode ser dito quando correlaciona-se faixa etária e tempo de navegação diário na internet, havendo correlação significativa do tempo diário de navegação com a variável idade, isto é, dos 200 entrevistados, 136 (68\%), nas diversas categorias de idade, mencionaram utilizar o celular para conexão, com significância estatística de 0,000 e coeficiente de contingência com significância de 0,000 (ou seja, inferiores a 0,05 ou 5\%). Também, na correlação estado civil (solteiro, casado, divorciado) com o principal meio de acesso à internet, o mesmo aconteceu (inclusive, com os mesmos índices de significância estatística). Já em relação à associação entre o tempo de navegação na rede social mais usada com as variáveis sexo, idade e estado civil, percebeu-se que a única correlação estatisticamente significativa apresentada esteve ligada ao estado civil dos respondentes; ou seja, de acordo com os dados coletados, dos 200 entrevistados, $173(86,5 \%)$ acessaram a rede social favorita todos os dias. Isso pode ser observado através do cálculo da estatística qui-quadrado entre estas variáveis, com significância estatística de 0,009, e com o cálculo do coeficiente de contingência, que mede a intensidade dessa associação, de 0,009. Portanto, verificou-se haver também uma forte e intensa correlação estatística entre a variável estado civil (solteiro, casado e divorciado) e a variável tempo diário de navegação na rede social preferida que, como visto anteriormente, foi o Facebook. 


\subsection{INFLUÊNCIA DOS POSTS NAS REDES SOCIAIS VIRTUAIS NAS ESCOLHAS DE DESTINOS TURÍSTICOS}

Pôde-se verificar que as postagens referentes às experiências já vivenciadas por algum indivíduo ou grupo têm grande influência para aqueles que ainda desejam realizá-la. Isso porque, $73 \%$ dos respondentes afirmaram ser importante ou muito importante este tipo de postagem; e apenas $27 \%$ da amostra disseram não ser influenciados por este tipo de postagem nas redes sociais (abaixo será descrito que essa influência tem predominância nas categorias de amigos e familiares). Esta porcentagem pode explicar também certa ineficiência das mensagens publicitárias das empresas nas redes, pois, $50 \%$ dos respondentes afirmaram que as mesmas não eram importantes; enquanto a outra metade afirmou que sim. Isso mostrou, mesmo de forma preliminar e não probabilística, que os relatos das experiências das pessoas próximas ao indivíduo nas redes apresentaram um maior peso em comparação às mensagens publicitárias das empresas, visto que, é característica principal no ambiente das redes sociais estabelecer vínculos com aqueles que já visitaram algum destino específico, e suas opiniões sobre o mesmo, ao invés de acreditar fielmente naquilo que as empresas estão afirmando sobre tal.

Isso pode ser afirmado, pois, ao analisar o tipo de indivíduo e os grupos com os quais os respondentes mais interagiam durante o tempo de navegação nas redes sociais (desconhecidos, conhecidos, amigos, família e empresas), percebeu-se que o grupo "Amigos" apareceu como predominante nas respostas, o equivalente a 79,3\% da amostra; seguido por familiares $(15,7 \%)$. Neste mesmo quesito, as empresas ficaram quase em último lugar, com $2 \%$ das respostas, perdendo apenas para as interações com desconhecidos $(0,5 \%)$; o restante dos entrevistados (2,5\% da amostra), afirmou não ser importante ou deixou de responder a questão. Isso mostrou o quanto a interação com a categoria "amigos" foi importante para os entrevistados, enquanto ocorreu o contrário quando se referiram à categoria "empresas".

Em sequência, buscou-se analisar a percepção dos respondentes acerca da influência exercida por posts nas redes sociais (fotos, vídeos e comentários) na escolha de um destino turístico para viajar. Nesta categoria, a maioria (65\% da amostra) afirmou que este tipo de informação teve influência na escolha do destino, sendo que destes, as 
postagens de amigos $(31,3 \%)$ foram as mais importantes, seguidas por familiares $(22,2 \%)$ e conhecidos (10\%). Aqui, mais uma vez, a influência das empresas, e de suas mensagens publicitárias, tiveram influência insignificante, com apenas 1,5\% das respostas (os outros 35\% disseram não sofrer influência ou não opinaram). Uma outra informação importante aqui é relativa à escolha de um destino completamente diferente daquele que o respondente costumava viajar a partir de um post nas redes sociais. Apesar da maioria dizer ter tido este tipo de comportamento (71,5\% da amostra), uma porcentagem significativa dos entrevistados disse que esse tipo de mudança de destino já havia ocorrido (28,5\%), e que, destes, as influências vieram principalmente de amigos (9,5\% da amostra), seguidos por familiares $(7,5 \%)$, conhecidos $(7 \%)$ e, por último, das empresas $(4,5 \%)$.

Ao realizar-se aqui o cruzamento das variáveis, como "a escolha de um destino turístico completamente diferente para viagem, a partir de posts nas redes sociais virtuais" e as variáveis "sexo" e "estado civil", apesar de não estatisticamente significativas as correlações, percebeu-se que os homens foram mais suscetíveis que as mulheres a fazerem este tipo de escolha, pois, dos 93 respondentes do sexo masculino nesta questão, 31 (ou seja 33\%) disseram já ter viajado para um destino completamente diferente a partir de post nas redes sociais; enquanto o percentual de mulheres caiu para 24\%, ou seja, das 107 mulheres que responderam à questão, 26 já haviam tido este tipo de comportamento. O mesmo ocorreu com a variável "estado civil", isto é, os solteiros responderam sofrer mais influências para mudar a viagem para um destino completamente diferente, pois, 32,8\% dos solteiros (41 dos 125 dessa categoria) disseram já ter praticado essa mudança a partir de posts nas redes sociais; enquanto os casados, 16 dos 59 respondentes também o praticaram, o que correspondeu a uma porcentagem menor, ou seja, a $27 \%$ daqueles que disseram sim nesta questão.

Algumas questões teórico/práticas importantes podem ser levantadas aqui, apesar de, como dito, a amostra adotada na pesquisa ser não-probabilística por conveniência, não havendo, portanto, possibilidade de generalização dos resultados.

Em se tratando de questões de ordem empírica, percebeu-se, a partir das análises dos dados deste tópico, que a maior influência nas escolhas dos indivíduos nas redes sociais foi exercida pela categoria "Amigos", seguida pela influência da categoria "Familiares" e "Conhecidos", sendo que os homens e os solteiros tenderam a ser mais 
influenciados tanto por amigos, quanto por familiares, a mudarem completamente o roteiro de viagem que já estavam acostumados a realizar, em relação ao sexo feminino e à categoria casados. Também, é importante destacar que as "Empresas" apareceram como exercendo influência mínima sobre os indivíduos pesquisados, perdendo somente para a categoria "Desconhecidos" (como visto na descrição dos dados feita anteriormente).

Já destacando questões de cunho teórico, em relação às mídias digitais e o turismo, em especial, as redes sociais virtuais, percebeu-se que os conteúdos produzidos pelo consumidor (consumer generated content), tinham gerado grande influência nos comportamentos de compra de produtos turísticos, a partir de um modelo igual-paraigual (peer-to-peer), visando o compartilhamento de informações (MIGUÉNS; BAGGIO; COSTA, 2008). Considerou-se poder afirmar, seguramente, a partir dos resultados, haver uma grande interação entre indivíduos online, através das redes sociais (MIGUÉNS; BAGGIO; COSTA, 2008; XIANG; GRETZEL, 2010; STRAUSS; FROST, 2012), foco deste estudo. E que, como destacado no referencial teórico acima, os operadores do produto turístico, representados aqui de forma genérica pela categoria "Empresas", enfrentam um consumidor mais ativo e participativo, que facilmente acessa informações e compartilha opiniões e sugestões, de modo informal e colaborativo, influenciando o poder de escolha de outros consumidores (MIGUÉNS; BAGGIO; COSTA, 2008); mostrando que as mensagens publicitárias online estavam perdendo sua força de persuasão para com estes indivíduos pesquisados. Também, que os laços fortes, principalmente a partir das categorias "Amigos" e "Família" se destacaram nas influências exercidas nas redes sociais, ao se escolher um destino de costume, ou um completamente diferente do usual. Os laços fortes são constituídos por familiares, amigos próximos e pessoas com profundo e influente envolvimento emocional. Já os laços fracos, representados aqui pelas categorias "conhecidos", "desconhecidos" e também pelas "empresas" (que, no início da pesquisa, geravam dúvidas de pertencimento aos laços fortes ou fracos), haviam gerado influência mínima no comportamento de escolha dos indivíduos pesquisados. Como apresentado, apesar de trazerem inovações aos indivíduos, através de novas ideias e comportamentos, os laços fracos são mais superficiais e com pouca profundidade emocional (GRANOVETTER, 1973); o que foi comprovado, de certa forma, pelos dados da pesquisa, pois, estas 
inovações, relativas à escolha de destinos e novos destinos pelos consumidores, vinham também de suas relações com seus laços fortes, ou seja, amigos e familiares, descredenciando, de certa forma, a força dos laços fracos proposta por Granovetter (1973). Isso pôde ser confirmado a partir das questões conceituais de Krackhardt (1992), pois o mesmo destaca, ao contrário de Granovetter (1973), a força dos laços fortes. De acordo com o mesmo, como destacado no referencial teórico do estudo, a força dos laços fortes está presente em situações de severas mudanças e incertezas, e que estes laços constituem a base de confiança que podem reduzir a resistência e proporcionar conforto em face da incerteza. Portanto, o autor destaca que a mudança não é facilitada por laços fracos, e sim, por um particular tipo de laço forte, ou seja, philos, a partir de três condições: interação, afeição e tempo. Portanto, este estudo reforça as questões conceituais levantadas por Krackhardt (1992) e, consequentemente, a força dos laços fortes nas relações presentes nas redes sociais virtuais na escolha de um destino turístico.

\section{CONSIDERAÇÕES FINAIS}

O objetivo geral deste artigo foi analisar a influência das redes sociais virtuais no comportamento de escolha de destinos turísticos por indivíduos. Para atingir este objetivo priorizou-se uma abordagem interdisciplinar e multiparadigmática, destacando teorias de mercado, de vertente funcionalista, com teoria de base sociológica, de viés mais interpretativo. Desta forma, buscou-se compreender, inicialmente, o conceito de cibercultura, termo que contextualiza toda a discussão proposta e, após, seus desdobramentos nas relações estabelecidas entre indivíduos e o composto turístico, tendo como intermediário seus desdobramentos nas redes sociais virtuais e nos laços sociais que unem e influenciam indivíduos e grupos nos seus processos de decisão de escolha que, neste caso, de um destino turístico.

Como pôde ser percebido na apresentação dos resultados da pesquisa, a redes sociais virtuais estão tendo, na atualidade, grande influência no processo de decisão de escolha de destinos turísticos por indivíduos, a partir de seus relacionamentos nas redes sociais. Observou-se isso, nessa pesquisa, principalmente a partir de seus contatos em 
suas redes de amigos e familiares, ou seja, de seus laços fortes. Isso porque, por meio de conteúdos produzidos pelo consumidor (consumer generated content), através de um modelo igual-para-igual (peer-to-peer), presentes em seus elos de amizade e aconselhamento, as pessoas participantes da pesquisa disseram ser amplamente influenciadas por eles. Um outro fator importante levantado pela pesquisa é que, ao contrário do delimitado por Granovetter (1973), são através dos conteúdos produzidos laços fortes nas redes sociais, que estes indivíduos tomam suas decisões, mesmo quando ocorre o processo de inovação que, neste caso, é a escolha de um destino turístico completamente distinto daquele que estes mesmos estavam acostumados a realizar suas viagens, reforçando o conceito de philos delimitado por Krackhardt (1992). Também e, finalmente, não se deve deixar de expor o enfraquecimento dos elos e influências que ligam as empresas aos indivíduos neste processo de decisão, visto que, as mesmas, nessa pesquisa, geraram influências quase que insignificantes por meio de suas publicidades online, perdendo apenas para a categoria "desconhecidos".

É importante relatar também aqui os pontos fortes e fracos da pesquisa realizada. Um dos pontos negativos a serem avaliados consiste na limitação da amostra e sua característica não-probabilística e o curto espaço de tempo de aplicação dos questionários, ou seja, a amostra poderia, mesmo sendo não probabilística, ter trabalhado com cotas de idade, sexo e faixa etária, o que tornaria a discussão proposta mais clara e segmentada; ou, pela adoção de uma amostra probabilística, mas que demandaria mais tempo e maiores custos de execução. Como pontos positivos, pode-se destacar a possibilidade de se discutir um tema de pesquisa de forma complexa, interdisciplinar e multiparadigmática e a realização de um estudo de viés quantitativo, pouco destacado nas pesquisas que envolvem o turismo enquanto ciência. É necessário mencionar, finalmente, que estas possibilidades, ligadas aos pontos fracos da pesquisa, podem influenciar outros pesquisadores da área, na busca de resultados mais amplos, a partir de amostras mais abrangentes e de adoção de técnicas multivariadas para a interpretação dos dados coletados. 


\section{REFERÊNCIAS}

AKTOUF, O. O simbolismo e a cultura de empresa: dos abusos conceituais às lições empíricas. In: CHANLAT, J. F. (Org.) O indivíduo na organização: dimensões esquecidas. Trad. Maria Helena C. V. Trylinski. São Paulo: Editora Atlas, 1994.

BIZIRGIANNIA, I; DIONYSOPOULOU, P. The influence of tourist trends of Youth Tourism through Social Media (SM) \& Information and Communication Technologies (ICTs). Social and Behavioral Sciences, 73, 2013.

BUHALIS, D.; LAW, R. Progress in information technology and tourism management: 20 years on and 10 years after the Internet - The state of eTourism research. Tourism Management, volume 29, issue 4, august, 2008.

BURREL, G.; MORGAN, G. Sociological Paradigms and Organisational Analysis: Elements of the Sociology of Corporate Life. Ashgate Publishing Limited: England. 2005. 184 p.

CASTELLS, M. A sociedade em rede. São Paulo: Paz e Terra, 1999.

CARVAlHO, E. de A. Para uma Ciência Geral da Complexidade Social. Perspectivas: São Paulo, 23, p. 11-23, 2000.

CHUNG, J. Y.; BUHALIS, D. Information needs in online social networks. Information Technology \& Tourism, volume 10, issue 4, 2008, p. 267-282.

DURHAN, E. Cultura e ideologia. Revista de Ciências Sociais, Rio de Janeiro, 27 (1), 1984.

FLEURY, M. T. L.; SAMPAIO, J. dos R. Uma discussão sobre cultura organizacional. In: . (Org). As pessoas na organização. São Paulo: Editora Gente, 2002.

GEERTZ, C. A interpretação das culturas. Rio de Janeiro: Guanabara Koogan S.A, 1989.

GUIMARÃES, A. S.; BORGES, M. P. E-Turismo: internet e negócios do turismo. São Paulo: Editora CENGAGE LEARNING, 2008.

GRANOVETTER, M. S. The strength of weak ties. American Journal of Sociology, vol. 78, issue 6, May, 1973.

HAIR, J. F. Jr.; ANDERSON, R. E.; TATHAM, R. L.; BLACK, W. C. Análise Multivariada de Dados. 5. ed. Porto Alegre: Bookman, 2005. 593 p.

HUDSON, S.; ROTH, M. S.; MADDEN, T. J.; HUDSON, R. The effects of social media on emotions, brand relationship quality, and word of mouth: An empirical study of music festival attendees. Tourism Management, 47, 2015. 
KRACKHARDT, D. The strength of strong ties. In: NOHRIA. N; ECCLES, R. G. (Eds.). Networks and organizations: Structure, form and action. Boston: Harvard Business School Press, 1992.

LEVY, P. Cibercultura. São Paulo: Ed. 34, 1997.

LITVIN, S. W.; GOLDSMITH, R. E.; PAN, B. Electronic word-of-mouth in hospitality and tourism management. Tourism Management, 29, 2008.

MAlHOTRA, N. K. Pesquisa de marketing: uma orientação aplicada. 3. ed. Bookman, 2001. 719 p.

MIGUÉNS, J.; BAGGIO, R.; COSTA, C. Social media and Tourism Destinations: TripAdvisor Case Study. Advances in Tourism Research. Aveiro, Portugal, May, 2008.

MINASI, S. M.; SILVEIRA, R. L. L. da. Redes sociais e turismo: reflexões no contexto do desenvolvimento regional. Revista Turismo e Sociedade, Curitiba, v. 9, n. 2, p. 119, maio-agosto, 2016.

MORGAN, G. Imagens da organização. São Paulo: Atlas, 1996.

SECOM. SECRETARIA DE COMUNICAÇÃO SOCIAL. Pesquisa Brasileira de Mídia 2016. Disponível em:

$<$ http://www.secom.gov.br/atuacao/pesquisa/lista-de-pesquisas-quantitativas-e qualitativas-de-contratos-atuais/pesquisa-brasileira-de-midia-pbm-2016.pdf/view>. Acesso em maio de 2017.

SCHULTZ, M.; GRUYTER, V. de. On studying organizational cultures: Diagnosis and understanding. Berlin: Walter de Gruyter, 1995.

STRAUSS, J.; FROST, R. E-marketing. São Paulo: Pearson, 2012.

TRIVIÑOS, A. N. S. Introdução à Pesquisa em Ciências Sociais: a pesquisa qualitativa em educação. São Paulo: Editora Atlas, 1992.

XIANG, Z.; GRETZEL, U. Role of social media in online travel information search. Tourism Management, volume 31, issue 2, april, 2010.

XIANG, Z.; WÖBER, K.; FESENMAIER, D. R. Representation of the online tourism domain in search engines. Journal of Travel Research, 47 (2), 2008.

Recebido em: 18-04-2017.

Publicado em: 18-05-2017. 